\title{
PS POLÍTICA DE VIDA Y MUERTE. APUNTES \\ wWw.aibr.org \\ PARA UNA GRAMÁTICA DEL SUFRIMIENTO DE LA GUERRA EN LA SIERRA DE LA MACARENA.
}

\section{Nicolás Espinosa}

Profesor del Departamento de Antropología, Universidad Nacional de Colombia.

\begin{abstract}
Resumen
La Sierra de La Macarena es una región colombiana donde se cruzan una serie de conflictos asociados a la colonización del piedemonte amazónico, al enfrentamiento entre el Estado y la guerrilla de las FARC, y a la presencia de cultivos de coca. Esta situación ha redundado en la vida diaria de sus habitantes, pues el conflicto regional ha configurado una serie de pautas y regulaciones para la vida social, comprendidas en este artículo como gramática social, a partir de las cuales los campesinos sobrellevan la situación. El trabajo se sustenta en una serie de narrativas recogidas durante una experiencia etnográfica realizada en la región de estudio; estas narrativas fueron de-construidas en función de la forma en que la población campesina asume las experiencias de sufrimiento ligadas al conflicto armado. El análisis es realizado desde la definición de tres momentos que comprende el sufrimiento social: la experiencia del sufrimiento, la representación social de éste y la racionalización subjetiva con que es asumido y naturalizado.
\end{abstract}

\section{Palabras clave}

Sufrimiento social, Conflicto Armado, Guerrilla, Colonización, Coca, Sierra de La Macarena.

\begin{abstract}
In the region of La Sierra de La Macarena in Colombia there apears some conflicts associated to the colonization of the Amazonican Piedemonte, the confrontation between the State and the FARC guerrilla, as well as the presence of coca plant crops. This situation has impacted in the everyday life of the habitants, as the regional conflict has created norms and rules in the social life of the community, that are considered in this article with the name of social grammar. This paper is based on some narratives collected during an ethnographic experience in this region, and they were de-constructed according to the way in which the peasants is assuming the suffering of the experience associated with the armed conflict. The analysis is based on three moments of the social suffering: The experience of suffering, the social representation of suffering and its subjective social representation, as well as the subjective rationalization by which it is assumed and naturalized.
\end{abstract}

\section{Key words}

Social suffering, Armed Conflict, Guerrilla, Colonization, Sierra de La Macarena

Agradecimientos 
Agradezco al profesor del Departamento de Antropología, César Abadía, pues gracias a su seminario "Sufrimiento, desigualdades sociales y desarrollo" se abrió una nueva línea de análisis para mi trabajo en La Macarena.

\section{Introducción}

$E_{s}^{n}$ n julio de 2005 durante una visita que realicé a varias familias campesinas de la Sierra de La Macarena, fui testigo de una serie de acontecimientos asociados al conflicto armado que dieron pie para la redacción de una etnografía titulada "Macarena Open 2005", presentada en el IX Congreso Colombiano de Antropología (Santafé de Antioquia). De este trabajo recojo algunos de los testimonios y vivencias de los que me valgo para la elaboración del presente artículo, donde pretendo abordar temas relativos a la forma como los campesinos de La Macarena experimentan y se representan las vivencias de vida y muerte, dolor y sufrimiento asociadas al conflicto social y armado. Dichas experiencias y representaciones las denomino gramática del sufrimiento en la medida que la dimensión social de éste ${ }^{1}$ ha moldeado las formas en que la colectividad y los individuos se comportan y asumen las reglas que impone la situación de guerra en que viven.

En el artículo intento desarrollar una propuesta de acercamiento conceptual y metodológico donde de-construyo el trabajo etnográfico que he realizado en La Macarena ubicando en las anotaciones y apuntes la definición de unas pautas que dan cuenta de una textura y una textualidad regional desde las que se puede observar la estructuración social de La Macarena. Estas dos figuras metafóricas me han permitido definir, en primer lugar, aspectos físicos y sociales que estructuran la región (la textura) y, en segundo lugar, las representaciones y significados con los cuales se les dota de sentido (la textualidad).

La textura regional se enmarca en una dinámica de Violencia Estructural (Farmer, 2003) que en su momento motivó el proceso colonizador y que en la

\footnotetext{
${ }^{1}$ Los editores de la serie de trabajos sobre sufrimientos social y violencia, Veena Das, Arthur Kleinman y Margaret Lock, definen sufrimiento social como aquellos "problemas humanos que tienen sus orígenes y consecuencias en las devastadoras heridas que las fuerzas sociales pueden infligir en la experiencia humana" (1997:IV). Dicen los editores que el sufrimiento es una experiencia social, y dada su condición esta experiencia tendrá que ser relacional, pues al analizar los casos que he tomado de mis apuntes de campo relativos a experiencias de sufrimiento en La Macarena, aunque el dolor tenga una dimensión subjetiva la forma como se asume en la región obedece a formas colectivas conocidas y reconocidas, o bien de forma explícita o por medio de estrategias implícitas que serán tratadas más adelante.
} 
actualidad propicia la existencia de los cultivos de coca como principal, por no decir única, fuente de ingresos económicos en la región. Como víctimas de la violencia estructural se entiende a las personas que han experimentado la violencia asociada a su extrema pobreza (Kleinman et al., 1997: 227). Este tipo de violencia se asocia a la "violencia de todos los días" (Scheper-Hughes, 1992; Kleinman, 2000) que encuentra distintas manifestaciones no solo en su dinámica sino también en su configuración, según sea la población afectada o bien por la violencia estructural y/o por las respuestas que desde esta se genera. La pertinencia de la perspectiva de violencia estructural aporta elementos para comprender cómo las FARC encuentran en La Macarena y en general las zonas campesinas deprimidas del país no sólo una base social proclive a sus propósitos sino una fuente de hombres y mujeres que desde hace 50 años engrosan en mayor número sus filas. En síntesis, sobre un escenario o una textura de violencia estructural se desarrollan las experiencias de la violencia en la vida diaria campesina y las textualidades que de esta se derivan, textualidades que a la manera de narrativas, representaciones y practicas sociales me propongo analizar en el presente artículo.

La situación de conflicto social que se vive en la región, traducida a una serie de experiencias de violencia de la vida diaria, no sólo se han hecho normales sino que también han normalizado los comportamientos de los campesinos a partir del eje articulador de la violencia de la vida diaria, la gramática social. Gramática que implica aquella serie de reglas implícitas propias del sentido común regional que configuran y se reproducen en las prácticas sociales de los campesinos.

A fin de ilustrar esta propuesta el texto lo he dividido en tres partes. En la primera abordo aspectos metodológicos sobre el ejercicio etnográfico y algunas consideraciones del área de estudio. En la segunda parte analizo algunos casos reales de experiencias campesinas de sufrimiento social a partir de un esquema que empieza por ofrecer las experiencias, luego comprender las representaciones sociales de estas y más adelante explicar la forma como se racionalizan en la vida diaria de los campesinos. Finalmente concluyo con un apartado en el que recojo algunas de las implicaciones de la dimensión social del sufrimiento en la configuración de la sociedad regional. 


\section{Construcción y de-construcción etnográfica}

\section{Pre-texto etnográfico}

De manera similar a como lo hace la fotografía, el ejercicio etnográfico apunta a captar imágenes de la realidad social, en cierta medida participar de ellas y traducirlas en un texto. Dicho texto, como imagen re-producida, se construye desde las observaciones realizadas y experiencias vividas, los testimonios recogidos, los discursos escuchados, las narrativas consultadas. Esa re-construcción del mundo social es uno de los principales debates que ronda a la antropología toda vez que, como lo llamara Rosaldo (1991), la subjetividad en el análisis social pone en entredicho las pretensiones objetivistas de una ciencia que se propone construir conocimiento riguroso, pero que no pretende ser exacta en tanto se puede valer de los mas variados recursos para aprehender las imágenes de la realidad social estudiada. Ahora bien, siguiendo la propuesta metodológica de V. Das quien plantea que algunas realidades necesitan ser hechas ficción antes de ser aprehendidas (1997), trabajar el registro de aquello imaginario que se construye desde lo real, y que a su vez construye lo real desde dimensiones simbólicas (lo real, lo simbólico y lo imaginario, tres registros que formuló Lacan para comprender la psique humana) constituye entonces un trabajo que conceptualiza a la sociedad en si misma (Das 1997: 68).

Para abordar el sufrimiento social en La Macarena adopto una serie de metáforas sobre lo imaginario que se enmarcan en varios momentos y lugares que la etnografía multisituada, tal y como definiera Marcus (1995). Se propone ante el reto que supone el análisis de lo local sin perder de vista las condiciones globales que pueden influenciar la realidad estudiada. Para el caso de La Macarena un estudio detallado de la configuración del conflicto armado implicaría tener en cuenta discursos hegemónicos de la lucha norteamericana contra el terrorismo que derivan en la financiación actual de la ofensiva militar en el suroriente del país (Plan Patriota), o las políticas de lucha contra las drogas que tradicionalmente los gobiernos colombianos han cumplido de forma tan juiciosa a partir de los intereses norteamericanos, exigencias europeas y supervisión de la ONU (Thoumi, 1997; Tokatlian, 1997). Política antidroga con agentes globales, nacionales y locales que 
moldean la forma, por ejemplo, en que la erradicación forzada de las plantaciones de coca se adelanta en la zona occidental de La Macarena. Estas condiciones tienen que ver sin duda en la configuración social de La Macarena, y vale la pena mencionarlas para tener una perspectiva global de situaciones que parecieran estrictamente locales, como lo son el poder regional que ejercen las FARC y la respuesta militar que reciben desde el estado. Pero son condiciones que trascienden los alcances propuestos para este artículo, pues el carácter multisituado que me he propuesto definir apunta, por un lado, a ubicar geográficamente el análisis en la región de La Macarena. En segundo lugar, a ubicarme en un ejercicio deconstructivo del trabajo etnográfico, pues realizado con anterioridad, para este trabajo me valgo de una relectura de las anotaciones, impresiones y entrevistas que aunque no fueron planteadas con el propósito analítico del artículo, me han permitido observar dimensiones del sufrimiento social que cumplen un importante papel en la configuración y codificación de la vida social y política en la región.

\section{Contexto etnográfico}

"Zona Roja" ha sido el lugar común para definir lugares como La Macarena, donde la presencia guerrillera parece resumir las condiciones y características regionales. La inmediatez del conflicto armado en la región no escapa a simple vista: retenes del ejercito, fuerte presencia militar y policial, controles a la movilidad, eternas requisas, precauciones de los conocidos ("mejor no vayan a tal vereda", "no caminen luego de las seis de la tarde"), comunicados de la guerrilla, emisoras radiales de las Fuerzas Armadas y de las FARC que compiten por audiencia; rumores sobre combates, deserciones, ajusticiamientos, en fin. La guerra está allí y no es difícil atestiguarla.

A la región se accede por carretera (desde el depto. del Caquetá), por río (desde el depto. del Guaviare) o por avión (desde Villavicencio, capital del depto. del Meta). La carretera desde Caquetá respeta el camino que trazaron los primeros colonos que en 1953 llegaron por primera vez a La Macarena (Molano, 1988). La carretera la construyó la guerrilla durante el tiempo en que se desarrollaron las fallidas conversaciones entre las FARC y el gobierno de Pastrana, en noviembre de 1998 y febrero de 2002, tiempo durante el cuál fueron desmilitarizados cinco municipios, 
entre ellos La Macarena, como exigencia de las FARC para adelantar el proceso. El viaje por avión sigue una ruta que, desde los años 60, condujo en aviones de la Fuerza Aérea a varias oleadas de campesinos que buscaron refugio ante los últimos rezagos de la época llamada "la violencia" (Guzmán, 1962). Otros tantos lo hicieron buscando mejores condiciones de vida gracias a las bonanzas que ofrecía la región: pieles, pescado, madera, marihuana, coca (Sierra, 1995).

Una vez allí, me ha llamado la atención cómo, a pesar de ser una zona llamada de forma común "zona guerrillera o zona roja" significa para sus pobladores el más común de los lugares. Es decir, la vida social ha pasado por un proceso histórico de adaptación al conflicto donde la vida de los pobladores actuales, los hijos y los nietos de los colonos (Trejo, 2002; Espinosa, 2003), ha heredado de sus predecesores una serie de prácticas sociales que han hecho que la vida en torno al conflicto social y armado sea una circunstancia cotidiana, gracias a una normalización y naturalización de la realidad que ha ajustado los comportamientos esperados, moldeado los discursos permitidos y, en suma, configurado la sociedad regional.

Indagar sobre lo cotidiano cuando lo cotidiano de la guerra, a pesar de lo problemático, es tan "normal" significa todo un reto. Siguiendo a Elias (1998) puede uno suponer que es posible comprender lo cotidiano en la medida que se tenga claro que es lo no-cotidiano. La convivencia, por tanto, como observación directa, participante y sostenida en el tiempo es la principal herramienta de una metodología de investigación etnográfica que no permite recetas estrictas. Conocí y llegué a la región gracias a una experiencia voluntaria de educación en escuelas rurales del municipio, situación que me permitió construir lazos de confianza con algunas familias en determinadas veredas. La presencia constante que he mantenido en la región es una de las llaves que me ha permitido abrir puertas en comunidades campesinas que, por naturaleza y como es normal en la región, son bastante reservadas. Puede uno hablar con los campesinos sobre asuntos propios de la vida campesina, de la educación, de las creencias y leyendas, pero tratar temas del conflicto cuando a varias personas les ha costado la vida hablar de más, sea quizá además del ejercicio de descifrar la cotidianidad el reto mas importante que como investigador he enfrentado. Superar la desconfianza y generar credibilidad no aparece en un manual de investigación y es el paso clave para acceder a la 
narrativa campesina, reglas muy similares a aquello que escribió Patricia Lawrence sobre cómo, para hablar de la violencia sufrida, existe la necesidad básica de un espacio seguro y un testigo seguro (1997: 221). El espacio seguro lo da una casa en horas de la noche, ante una grabadora apagada y sin notas de por medio. La posición que como académico tengo ante las comunidades, donde académico es alguien con estudios universitarios que viene de "afuera", y la apuesta política expresada sobre compartir su realidad con otros espacios y otras personas en el país ha servido para fomentar reconocimiento a mi trabajo y ofrecer seguridad. Que en todo caso ante necesidades sociales más apremiantes, la pertinencia de la investigación social puede quedar, seguramente, en algo anecdótico. Si investigo es para algo y ese algo es mostrar aquello que no se muestra. He recorrido la región desde 1998, allí realicé durante dos años el trabajo de campo para mi trabajo de grado indagando sobre la relación entre las comunidades campesinas y la guerrilla, y publicado varios artículos sobre los mecanismos de resolución de conflictos en la región y condiciones de la vida campesina. Bajo esa premisa, la de contar lo nocontado, sin evadir el debate sobre la autoridad etnográfica y el criterio de verdad, he podido explorar narrativas regionales sobre la vida campesina y el conflicto armado en La Macarena de las que me valgo para realizar el presente artículo.

\section{Elementos constitutivos de la narrativa regional sobre el sufrimiento}

La ficción como estrategia para comprender la realidad reincorpora el registro de lo imaginario como parte fundamental en la comprensión de "lo real". La conceptualización de la sociedad por esta vía, tal y como ha sido propuesto por Das (1997:69), me inspira el plantear una forma de interpretación antes mencionada en la introducción desde la que reconozco tres momentos que recorre el proceso del sufrimiento social en La Macarena: la experiencia, la representación y la racionalización, del dolor y el sufrimiento. Esta es una estrategia analítica para aprehender esta realidad desde el registro de lo real, lo simbólico y lo imaginario tal y como lo propusiera Lacan y que rescatara para su propuesta Veena Das, de quien tomo y adapto su fórmula para el ejercicio que continúa. 
¿Cómo viven los campesinos la experiencia de la guerra? Los siguientes ejemplos de dolor y sufrimiento como experiencias ligadas a la dinámica de conflicto armado que se vive en la región sirven de telón de fondo para el análisis del presente ensayo. Los límites del trabajo plantean un análisis mas focalizado a la relación de la guerrilla con las comunidades, y el ejercicio del poder local, sin que por esto pretenda excusar el papel que juega el estado en cuanto a su responsabilidad ante el sufrimiento social, por acción u omisión. La disparidad en la experiencia del sufrimiento infringido, bien sea de parte de la fuerza pública o de la guerrilla, marca diferencias estructurales en la definición del discurso político campesino, puesto que las agresiones institucionales se conciben de manera distinta a las agresiones insurgentes. La resolución de esta versión de la "dialéctica de la confrontación" pasa por el establecimiento de estrategias bélicas que desde la guerrilla y la fuerza pública desnaturalizan a los civiles como civiles, asimilándolos como combatientes y por ende posibles objetivos militares. La agresión desde el estado es parte fundamental de la narrativa campesina de victimización que contribuye a la definición particular de "lo político" en la región donde el conflicto armado escapa a la pura confrontación militar, pues el ejercicio de la confrontación pasa por una concepción territorial desde las FARC y el estado que involucra a las comunidades campesinas como un escenario social en el que se reproduce la contradicción política y por lo tanto es un campo de lucha de una forma mas literal que figurada. Las agresiones insurgentes, en cambio, son asumidas de distintas formas y con más matices de cómo se asumen las agresiones oficiales.

\subsection{La experiencia (lo real)}

"Algo tenía que deber..."

"El Pollo" fue uno de los campesinos que discutió con mayor vehemencia los presupuestos con los que trabajé algunos aspectos de la relación entre los campesinos y la guerrilla en La Macarena. Su discurso, aunque nostálgico por la experiencia de la Unión Patriótica ${ }^{2}$ era bastante crítico con las FARC, pues no

\footnotetext{
${ }^{2}$ Movimiento político que acogió a numerosas fuerzas sociales, cívicas y de izquierda, entre ellas miembros de la guerrilla, que tras fundarse gracias la tregua decretada por las FARC en 1984 durante 
compartía la forma autoritaria como esta guerrilla se relacionaba con las comunidades. A pesar de ser un líder comunitario, pues era presidente de la Junta de Acción Comunal, se mantenía alejado de la actividad política. Según él, tantos muertos de la UP eran el mejor ejemplo que no hay condiciones para la participación de los campesinos en política. "Mientras haiga guerra no hay nada que hacer" insistía. Como todos los campesinos ante mis preguntas siempre se mostró reservado y cauteloso, incumplió muchas de las citas acordadas para entrevistarnos y finalmente tuve que quedarme en su casa varios días hasta que fastidiado de tanto verme cedió. Su interpretación jurídica sobre la forma como se resuelven los conflictos en la región y sus propuestas para un mejor desarrollo de esta actividad abrieron nuevos horizontes para mi trabajo y redefinieron la orientación académica que desde entonces acogí. Un año después, cuando me encontraba redactando el texto final de mi trabajo, me enteré de su muerte. Le había enviado con anterioridad cartas y presentes, pero sus familiares decidieron guardar esta noticia varios meses hasta el día en que me llamaron.

La guerrilla "ajustició" a "EI Pollo" mientras trabajaba en una finca cercana a su casa. A finales de 2002 las FARC, no se sabe si deliberadamente o por una perversa coincidencia, ejecutó varios campesinos en la región todos los viernes de noviembre. La guerrilla había advertido meses antes que en la vereda "El Socorro" había un "sapo" que pronto iba a pagar sus cuentas. Según me comentaron varias personas mas de uno se sentía atemorizado en esos días puesto que en términos de efectividad la guerrilla es implacable, pero en eficacia no tanto. Es decir, ejecuta al que va a ejecutar pero "no siempre con razón". En el caso de "El pollo" las narrativas sobre la forma en que fue asesinado coinciden. Toda la vereda, incluso, asistió a su entierro. Pero las narrativas sobre su muerte varían, pues a excepción de la familia de "El Pollo" quienes hasta no verlo muerto no creyeron que lo hubieran matado "si él no le hacia nada a nadie", varios campesinos dejaban notar entrelineas que probablemente "El Pollo" si fuese un sapo. Tras su muerte las sospechas empezaron a aparecer. “¿Por que iba tanto al pueblo?”; "El Pollo” siempre criticaba a la guerrilla"; "A mi me dijeron que por un camino el pollo iba criticando a la guerrilla y la guerrilla lo escuchó y por eso lo mataron"; "El policía que recibió el cuerpo en el

el gobierno de Belisario Betancourt fue sometida a un proceso sistemático de exterminio desde grupos paramilitares y sectores de la fuerza pública que la hicieron desaparecer por completo. 
pueblo dijo "qué pesar, mataron al señor que siempre nos ayudaba"; "si lo mataron fue por algo".

"Yo no estoy de acuerdo con la pena de muerte, pero...."

En junio de 2005 un vecino de otra vereda llegó a casa de doña Magnolia, donde me estaba quedando por esos días. Tras el saludo y el recibimiento protocolario los dueños de la casa entraron con el vecino a la cocina y hablaron en voz baja. Al rato salieron. El vecino se despidió y en la noche me contaron el motivo de la visita: el día anterior la guerrilla asesinó a "el panadero" a pocos minutos de nuestra casa, dejando un cartel encima de él con una leyenda que decía "eso le pasa a los informantes del ejército". Eso explicaba el inusual movimiento de helicópteros que observamos ese día y que nos hizo presagiar algún tipo de combate. Comenté que yo no podría estar nunca conforme con la pena de muerte. Doña Magnolia quedó pensativa y afirmo que ella tampoco, al igual que su esposo, don Ramiro. Pero acto seguido completaron: "si, es cierto, yo no estoy a favor de la pena de muerte- afirmó don Ramiro- pero lo que pasa es que por culpa de uno pueden caer muchos". Doña Magnolia añadió: "además la guerrilla no mata porque sí, mata al que anda en malos pasos y no es correcto" (...). Su testimonio me dejó un tanto sorprendido. No sabíamos nada del panadero más que la razón que trajo el vecino: la guerrilla lo mató y dejó con él un cartel. Recordé que la familia de doña Magnolia estuvo en la mira de la guerrilla por mucho tiempo, fueron amenazados con el destierro y fueron ellos los encargados de realizar el levantamiento de "El Pollo" y gestionar su entierro, toda vez que él no solo era amigo de la familia sino que también era esposo de una hermana de don Ramiro.

\section{La injusticia toca la puerta}

La casa de don Ramiro fue allanada por el ejército sin orden judicial y en su ausencia. Dos de sus hijos, de 15 y 10 años estaban en la casa cuando un grupo de soldados encapuchados ingresó por varios lados haciendo destrozos. Llegaron buscando guerrilleros y preguntando por las armas escondidas; los dos niños fueron golpeados y al llegar don Ramiro y doña Magnolia los insultos y las amenazas 
arreciaron. La situación se calmó y la familia pudo convencer a la tropa que allí no había guerrilleros. Dieron de beber a los soldados y un año después, cuando me contaron su historia, saludaban en el pueblo a los soldados que ingresaron a su casa sin mostrar rencor aparente. Hace pocos meses, en el 2006, el hijo mayor de la familia, Gabriel, fue detenido por el ejército cuando caminaba con sus hijos por el pueblo y judicializado como guerrillero. Hoy día está en la cárcel a la espera de su libertad o la apertura formal de juicio. Entre tanto, en la región, corren rumores que hablan sobre una posible colaboración de Gabriel con las autoridades, pues no de otra manera la gente se explica que en un control policial hayan capturado a otro joven a quien la fiscalía acusa de complicidad con Gabriel. Algunas personas dudan que Gabriel esté en la cárcel y aseguran que este recibió una recompensa. La captura de Gabriel, que coincidió con la mudanza de su familia a Villavicencio ${ }^{3}$, hizo que los rumores se complicaran, pues para algunas personas el cambio de vida de la familia solo se explica por los supuestos tratos judiciales de Gabriel y el dinero que éste recibió. Una vez se compruebe la inocencia de Gabriel y salga de la cárcel la familia ha puesto en entredicho la conveniencia de que regrese, pues creen que la guerrilla puede pensar que si salió es porque ha hecho algún tipo de trato. Gabriel y su familia, por tanto deberán buscar nuevas formas de vida.

\section{La comunidad imaginada}

De Don Rogelio se dice que desde que llegó a La Macarena hace 30 años siempre fue simpatizante de la guerrilla. Fue uno de los fundadores de la vereda La Aguacatala, varias veces presidente de la Junta y un reconocido líder comunitario. Varias personas me han contado que en su casa los Comandantes guerrilleros siempre se detenían y que allí se realizaron más de una vez reuniones entre los alcaldes y los comandantes de turno. Una vez terminó el despeje el ejercito lo capturó en el pueblo mientras hacía el mercado y lo detuvo sin orden judicial en una casa junto a varias personas de la vereda El Roble, entre ellas un joven de 13 años, Ferney, que tiene dos hermanos en la guerrilla y vive en la vereda vecina, El Roble. La Junta de Acción Comunal de El Roble solicitó al ejército la libertad de Ferney, de quien dieron fe era un buen trabajador que nada tenía que ver con los asuntos de

\footnotetext{
${ }^{3}$ Capital del departamento del Meta.
} 
sus hermanos. De igual forma los miembros de la Junta de El Roble dieron su apoyo al vecino de la vereda contigua, Don Rogelio, y recogieron firmas y testimonios, acudieron a la personería municipal y solicitaron al Ejército su liberación. El ejército liberó a Don Rogelio y Ferney. El muchacho prefirió desde entonces nunca más volver al pueblo para no tentar la suerte y evitar una posible detención, a pesar de que no tiene ningún vínculo con la guerrilla. Don Rogelio, entre tanto, al ver que sus vecinos de la comunidad donde vive no le prestaron ayuda decidió inscribir su finca en la Junta de Acción Comunal de la vereda vecina y desde entonces la vereda El Roble es mas grande, pues ganó una familia y una finca más. Don Rogelio rompió todo lazo con la vereda que el fundó.

\subsection{La Representación (lo simbólico)}

No solo el escenario de conflicto genera las realidades de sufrimiento a que se exponen los habitantes de la región sino que también define los sentidos que adquieren las prácticas y las consecuencias de la guerra que allí se desarrollan. Siguiendo a Foucault (2003) la construcción de una disciplina para conseguir individuos plegados a las reglas es un proceso que se vale de la sanción ejemplarizante: aquellos desviados serán castigados. El problema de La Macarena, y de otras regiones del país, sucede cuando no es uno solo sino varios ejercicios de disciplinamiento los que entran en conflicto, con distintas variantes y formas de construir la legitimidad, sin importar que para ello se de-construya y contradiga la legitimidad: la lucha por el pueblo pasa por el ajusticiamiento de sus traidores, y la lucha por la institucionalidad puede pasarse por alto dicha institucionalidad.

"El ejercicio de la disciplina supone un dispositivo que coacciona por el juego de la mirada", escribió Foucault (2003: 175), donde el poder de esa mirada es casi inmanente. En los caminos no se habla, los temas comprometedores son proscritos y si acaso se realizaran en casa, el espacio es la cocina; nadie se deja ver con nadie comprometedor. La guerra, más allá de las balas, se deja ver en una cotidianidad ineludible. Los ajusticiamientos ejemplarizantes, la persecución estatal son cosa común. 
La racionalización de los ajusticiamientos como "algo que le pasa al que la debe" se enmarca en un proceso de representación que naturaliza la situación. La política en la región es una política de vida y muerte donde la lucha por la vida pasa por la legitimidad de la muerte. "Por culpa de uno pueden caer muchos", sentenció don Ramiro ante el ajusticiamiento de "el panadero". Así como se vive, y se reivindica la vida, se deja morir como una estrategia perversa para seguir viviendo. Pocas veces alguien se atreve a contestar el poder de la guerrilla. Las muertes en la región viene cargadas de significado, donde como acto de matar, según lo propone la profesora Elsa Blair, éste comprende dos momentos: la ejecución y la significación (Blair, 2005: xxv). Al acto físico en si, propone la autora, lo suceden la interpretación, la divulgación y la ritualización como escenas desde las que se significa la muerte. Los asesinatos de "El Pollo" o "El Panadero", por ejemplo, se hicieron en la vereda de cada cual, a luz del día y con testigos cercanos. La interpretación inmediata, como se verá mas adelante, viene ligada a la razón de la muerte: los mataron por algo. La divulgación está asegurada porque, con la presencia de testigos, la información corre muy rápido en la región, y la ritualización como la sociedad afronta la muerte viene dada por la forma misma como esta se ejecutó: como advertencia, como ejemplo, como muestra de poder y presencia. El letrero que la guerrilla dejó encima de "El Panadero" no fue retirado por nadie sino hasta que el ejercito levantó el cadáver.

Este proceso de "naturalización" cuando la guerrilla asesina a alguien evoca una distancia en la que la responsabilidad social se diluye. Es decir, la construcción social de lo que significa el sufrimiento puede comprenderse como aquel viaje metafórico que realiza el sufrimiento experimentado en la orilla de la vida diaria hacia una orilla abstracta donde es representado ${ }^{4}$. Allí, en esa orilla abstracta, la violencia sobre alguien se moldea de tal forma que se reconstruye como un dolor y un sufrimiento abstracto, ajeno a los individuos y presumiblemente exógeno a la colectividad pues ha recaído en los que "algo deben".

Aun así, y a pesar de la distancia con que los individuos pretendan separar el sufrimiento ajeno del propio, ese sufrimiento naturalizado de tal forma asume una figura colectiva, pues aunque el asesinado, el desterrado, el amenazado sea

\footnotetext{
${ }^{4}$ Para esta analogía he tomado prestado la figura metafórica de S. Cavell: la filosofía como río que fluye entre dos orillas, la de la metafísica y la de la vida diaria (Das 1997:68). 
cercano, a todos les puede tocar la misma suerte. La forma colectiva de esta experiencia configura finalmente las expresiones y percepciones individuales (Kleinman y Kleinman, 1997: 2). Esas formas colectivas, dicen los autores antes citados, son patrones visibles en la manera en que se sobrellevan los problemas, donde estos son pensados y aprehendidos de forma directa o indirecta (2). Esta tensión entre el sufrimiento colectivo y su traducción subjetiva implica que, según estos autores, "las representaciones culturales autorizadas por una comunidad moral y sus instituciones elaboran diferentes modos de sufrimiento. Así las diferencias locales -genero, edad, grupo, clase, etnicidad, y por supuesto, subjetividad- como también la penetración de un proceso global en mundos locales hacen de esta influencia social parcial y compleja" (3). De allí que las afrentas infringidas por el estado o por la guerilla sean distintas. Mientras que aquellas que provienen del estado victimizan a la población y la solidarizan, el papel hegemónico y si se quisiera casi "legítimo" (en términos políticos) de la guerrilla en la región se ha construido mas allá de la coerción. Siendo así que cuando la guerrilla mata, es por algo...

¿Cómo entender, entonces, no solo el sufrimiento sino las diversas formas como se presenta para su uso social? Esta inquietud implica una serie de retos conceptuales y de aproximación, pues como lo proponen Das y Kleinman "las transformaciones en las representaciones culturales y las experiencias colectivas de sufrimiento reconfiguran las respuestas interpersonales ante la catástrofe y el terror" (2001: 2; traducción propia). Martín Mora, al establecer una serie de características constitutivas de las representaciones sociales, apunta a proponer que la conciencia colectiva de la sociedad (en este caso una sociedad regional) construye una unidad de sentido que institucionaliza un saber normativo (2002: 6). Según esto aquellas personas que "algo deben" ya estaban advertidos, doble condición que refuerza la legitimidad de un ajusticiamiento en buena medida a que la experiencia colectiva de violencia a que esta sometida la región configura la individualidad y las respuestas subjetivas. Es el ya mencionado camino de la normalización de la situación, así que puede entenderse que la representación cultural del sufrimiento "lo moldea como una forma de experiencia social. "Las normas de alguna manera envuelven al sufrimiento dentro de la normalidad (y patología). La experiencia de sufrimiento, es aprendida, compartida y no frecuentemente contradicha" (Das 1997: xii; traducción propia). 


\subsection{La Racionalización (lo imaginario)}

Regresando nuevamente a los lugares comunes, la mención genérica y bastante abstracta del conflicto como fuente del sufrimiento, como responsable de las desgracias, como culpable de los crímenes, es un recurso frecuente en los agentes enfrentados en el conflicto armado, y en ocasiones entre las víctimas. En el caso de las FARC éstas edifican su discurso político a partir de la victimización. "Victimas de cinco guerras ${ }^{5 "}$ es quizá el recurso mas utilizado por ellos, donde la mención al ataque de Marquetalia se erige como su mito fundacional. Pero cuando se trata de afrontar los propios excesos y el papel que como victimarios llegan a jugar la culpable es, en abstracto, la guerra y el responsable el estado, pues éste no ofrece las condiciones de una negociación. Al respecto se puede apelar a la interpretación de Arthur Kleinman cuando afirma que "las memorias históricas del sufimiento, i.e. esclavitud, destrucción de comunidades aborígenes, metáforas, modelos- pueden ser ( $y$ frecuentemente lo son) apropiadas en la cultura popular o por instituciones políticas particulares para propósitos políticos y morales. Por esta razón el sufrimiento tiene un uso social" (1997: xii). En el caso del estado la argumentación ante su responsabilidad frente a los avatares de la guerra y aquellos que no lo son estrictamente pero que tiene que ver con excesos armados, tiende a ser similar a la argumentación de la guerrilla, pero de manera inversa. Quien agrede es la guerrilla y los errores propios son producto de "la guerra", y los culpables son las FARC, enemigos de la paz.

De aquella época negra en la historia del país llamada "la violencia" parece que heredamos la costumbre de abstraer las responsabilidades en realidades totalizantes. El lugar común propio de esta circunstancia histórica es que los más de 300 mil colombianos que murieron en aquel entonces lo hicieron "por culpa de la violencia" 6 . Hoy día a la violencia y a la guerra se le ha sumado el "lenguaje de los

\footnotetext{
${ }^{5}$ Véase www.farc-ep.org en la sección documentos.

${ }^{6}$ Al escribir el texto me sorprendí con la facilidad con que escribí esta cifra, pues no cuento con una referencia directa y no recuerdo a ciencia cierta donde me enteré sobre ésta. Quizás la cifra de las 300 mil muertes no cuenta con una fuente a quien referenciar porque, como otras tantas, como los 3.500 muertos de la U.P., hacen parte de un conocimiento colectivo compartido propio de los colombianos. En todo caso el libro de Monseñor Guzmán (1962) fue quien inspiró el uso retórico de la cifra en cuestión.
} 
actores" sobre el que llamara la atención el profesor F. Cubides acotando cómo la mención a los "actores armados" toma de la teoría de la acción social una connotación descriptiva con la que los paramilitares, en principio, pretenden legitimarse una vez declaran "somos actores armados" (Cubides 1998). Desde entonces es común el lugar que ocupa el lenguaje de los "actores", donde estos en abstracto son los responsables de la guerra, pero sobre los cuales se hace una salvedad: el discurso oficial habla de "actores armados ilegales" o "grupos armados ilegales". La fuerza pública no se concibe, en este discurso oficial, como grupo o actor armado ${ }^{7}$.

Las victimas del conflicto pueden remitir su condición de victimas a la responsabilidad abstracta, precisamente, de ese conflicto que parece difuminar culpabilidades individuales. "Somos desplazados por la violencia" es la firma que llevan los letreros de las personas que inundan lugares públicos en las ciudades, pidiendo colaboración, o es la firma con que se muestran en declaraciones públicas. Es una estrategia de supervivencia, claro está, porque dentro de la lógica "si lo desplazaron fue por algo" es fácil ser señalado de guerrillero si alguien dice "me desplazó el ejército o los paramilitares". En Macarena la situación observa una particularidad: la racionalización de la responsabilidad no es abstracta, no es etérea. Si alguien mató, si alguien desplazó, si alguien cometió algún atropello ese alguien tiene color: fue la guerrilla, fue el ejército e incluso tiene nombre o distinción: fueron guerrilleros del séptimo frente, fue el comandante Alejandro, fue tropa de la marina, fue tal sargento. La muerte de "El Pollo" tratada en los casos de la experiencia no fue a causa del conflicto, fue la guerrilla y fueron guerrilleros que en la vereda conocían. El allanamiento comentado fue hecho por tropas que los campesinos ya había visto por la región al mando de oficiales con quienes se saludan en el pueblo.

Esta cercanía quizá normalice más las situación de guerra en tanto situación que se espera es más previsible. Es decir, cuando el control tiene nombre propio, está regularizado, se sabe como actuar ante éste. Distinto sucede cuando no se sabe a ciencia cierta quien asesinó a una persona y por qué, o no se sabe quien ordena un comportamiento y por qué. Ante un conflicto que se presenta de forma tan abierta la racionalización de este es, entones, particular. El terror, el miedo, el control tiene distintos rostros pero son rostros reconocibles. El trabajo de M. Suárez

\footnotetext{
${ }^{7}$ Véase la página web del ministerio de defensa www.mindefensa.gov.co 
Speaking the Unspeakable (1990) propone una serie de mecanismos de defensa sicológicos desde los cuales entiende los procesos de racionalización e interiorización del terror. De su trabajo he tomado la noción de "racionalización" como estrategia constitutiva del proceso de asimilación del sufrimiento en la región de estudio. "El terror colectivo -apunta Suárez- como otros sistemas culturales, posee una estructura subyacente, su propia gramática" (366). Al encarar lo inenarrable el ego amenazado intenta contener la "deconstrucción del mundo" por medio de la negación, la racionalización y la interiorización y elaboración del terror. Bajo estos parámetros y al releer los casos que he recogido en La Macarena puedo encontrar aspectos de negación ("no creíamos que fuera él porque el no le hacía nada a nadie") y racionalización ("al que anda por el camino correcto nada le pasa"). Aún así este autor propone que el momento de la interiorización y elaboración del terror se da una vez la situación se ha calmado. El exilio o la superación total de la situación son los contextos que permiten que la elaboración del terror regrese en forma de una nueva conciencia de eventos e imágenes antes negadas, olvidadas o medio conocidas (366). En el caso de La Macarena, donde la situación está lejos de superarse y el exilio no es asumido por todos, la interiorización y elaboración del terror se da sobre la marcha y cuenta con estrategias que hacen de éste un proceso "normal" que ante situaciones anormales, similares a las que describe Ignacio Martín Baró en su trabajo "Guerra y Salud Mental" (1990), son algo por lo cuál no hay por qué preocuparse demasiado. "Hay que seguir adelante porque si no qué" me dijo alguna vez una campesina, resignada ante los hechos de violencia que se vivieron en la región tras una ofensiva militar.

La racionalización como sentido tiene sus límites. De forma similar a la propuesta de Suárez ${ }^{8}$, la falsa seguridad que otorgan las fórmulas "si lo mataron fue por algo", se circunscriben a una situación de normalidad condicionada que se rompe cuando las reglas de comportamiento que supuestamente la soportan, el "andar por el camino correcto", pierden toda garantía y cualquiera, entonces, es susceptible de ser castigado. Por ejemplo, ocurrió en La Macarena que en noviembre del año 2002 existió un ambiente de temor colectivo ante una serie de ajusticiamientos sumarios de la guerrilla a pesar que solo los que deben algo tienen

\footnotetext{
${ }^{8}$ El autor trabaja en el caso argentino la falacia del teorema "no estuve en actividades subversivas ergo no seré castigado" pues se comprobó que existieron asesinatos "por error" de personas que no estuvieron involucradas en actividades subversivas (369).
} 
que temer. Quizá el análisis pueda acogerse a la noción de sociedad traumatizada, donde de forma similar al trauma clínico, éste se refleja no solo en el cuerpo sino en la mente (Young, 1997: 245). Reflejo que asume la forma de "secreto patógeno" como acto de "auto decepción" donde la persona oculta de si la memoria de eventos inquietantes (247). Esto es clave, porque dice Young que "aún así, por fuera de la conciencia la memoria continúa afectando el comportamiento como fuente de sufrimiento" (247). Esto plantea un reto de características éticas, morales y políticas para la organización campesina en la región, para el discurso político guerrillero y para la proyección de políticas pos-conflicto del estado en cuanto a la facilidad paradójica con que históricamente se aceptan y se padecen, en tanto se olvidan (como acto consciente o estrategia inconsciente) distintas formas de sufrimiento que se somatizan en un olvido que siempre está presente, una memoria colectiva de carácter traumático; memoria que se hereda y se reconstruye. Es así que la noción de "ajusticiamiento" que rodea los asesinatos de carácter político o social, encarna una significación de justicia como aplicación de una sanción justa que debe ser discutida en la región, pues parece ser una noción que habiéndose sedimentado en la vida cotidiana se ha naturalizado de tal forma, junto con otras formas de control social, que aún hoy día con la memoria fresca sobre los hechos e injusticias del año 2002 la racionalización sobre las ejecuciones guerrilleras, como algo que alguien seguramente se merece, sigue reproduciéndose. Es cierto, la legitimidad política construida por la guerrilla entre sectores campesinos no es un hecho menor, pero dicha legitimidad y el posible reconocimiento con que puedan contar las FARC en la región no tienen porque dejar de lado que las injusticias y errores que pueden cometer, y que la experiencia demuestra han cometido, cuestan vidas y que las vidas perdidas son irreparables.

\section{Sociedad regional y gramática del sufrimiento.}

Dentro de los estudios de los movimientos armados y las revoluciones en América Latina el trabajo de T. Wickham-Crowley ofrece un panorama comparativo en el que se rescata la importancia de "la cultura" en la configuración de los movimientos insurgentes y sus posibilidades de victoria, pues por así decirlo en la sintonía cultural con que actúe una organización con su población de base se puede 
garantizar un suficiente apoyo. El carácter conflictivo del asunto radica en que, según propone el autor, la estructura cultural no es reductible necesariamente a la estructura social (1996: 130). Existen en nuestro país, por tanto, una serie de realidades culturales que se adecuan de forma distinta al conflicto armado y sus agentes. Ante semejante panorama analítico, donde las formas como la insurgencia y el estado se relacionan con las comunidades, y estas los sobrellevan, se encuentran muchas versiones dado que no se trata, pues, de un conflicto sustentado en un marco étnico que diferencie a dos grandes grupos poblacionales. Es decir, el conflicto colombiano no pasa por un enfrentamiento entre comunidades étnicas donde la base del mismo sea un "problema de la comunidad" (Spencer, 1997), tal y como sucede o sucedió en otros países (Sri Lanka, por ejemplo, cuya situación es analizada por el autor antes citado). Siendo así, en Colombia no existe una sino múltiples estructuras culturales que se sobreponen. Los estudios regionales, estudios de caso, cobran por tanto vigencia en el propósito de conocer el impacto del conflicto en las distintas comunidades étnicas y sociales que componen el país.

Con la guerrilla los campesinos viven a diario desde hace décadas, su poder en la región no se ve menguado por las acciones militares en su contra y a pesar de no haber consolidado un control territorial que supere la trashumancia propia de la estrategia irregular, su fuerza militar aun significa un desafío para el Estado. Durante el año 2003 asediaron el casco urbano de La Macarena más de un mes; a finales de 2005 atacaron un grupo de soldados causando 29 militares muertos. La lectura del gobierno nacional ligó la fuerza de ese ataque al avance de los cultivos de coca en la región, y como respuesta se embarcó en una campaña de erradicación de cultivos ilícitos. La réplica de las FARC no se hizo esperar y a comienzos de 2006 a pesar del avance del Plan Patriota, la más fuerte ofensiva contrainsurgente lanzada por el Estado colombiano, la guerrilla impuso un paro armado que se extendió durante dos meses en toda la región.

La lectura del conflicto que realiza el Estado colombiano no distingue entre campesinos, guerrilleros y narcotraficantes. La retórica oficial es fuerte y la respuesta militar lo es de manera proporcional, afectando directamente a los campesinos. Se considera desde el Estado que la producción de coca es una producción ligada al narcotráfico que lidera la guerrilla. Las políticas de erradicación de coca no contemplan programas alternativos de producción y en cambio criminalizan a los 
campesinos, no solo como narcotraficantes, sino también como guerrilleros. La vinculación de la lucha antidrogas en la lucha antisubversiva ha implicado para los campesinos, según testimonios que he recogido, detenciones masivas, cuando no arbitrarias; allanamientos sin orden judicial ni acompañamientos, bombardeos indiscriminados, constantes señalamientos y atropellos. Las acciones oficiales se traducen en el descrédito de la institucionalidad. $Y$ en términos de la violencia de todos los días implican nuevos marcos reguladores de las relaciones sociales.

Décadas de conflicto social, de conflicto armado, dejan su huella en la cotidianeidad de los campesinos de La Macarena. Para los habitantes de la región vivir en un panorama de guerra donde la guerra, mas allá de los combates entre las Fuerzas Militares y la insurgencia, se extiende al campo mismo de las relaciones sociales ha implicado que las experiencias de violencia y sufrimiento se hayan sedimentando en la identidad político/cultural de la región ${ }^{9}$. Estas experiencias se han integrado a la identidad de las comunidades mediante procesos de racionalización y representación de la violencia, reguladas por medio de una gramática social que impone una serie de condiciones sobre aquel comportamiento y aquellas respuestas permitidas a los campesinos frente a la violencia, frente al sufrimiento.

Las regulaciones son de variado orden: se encuentran en caminos y escuelas, en carteles donde las comunidades han establecido una normatividad social algunas veces amparada y legitimada por la guerrilla. Pero otro tipo de regulaciones no encuentran el carácter formal de la normatividad comunitaria o las "orientaciones" guerrilleras. Es de público conocimiento en la región que después de las seis de la tarde transitar por ríos y caminos no sólo es prohibido por la guerrilla, lo que da lugar a multas en caso de incumplimiento, sino también peligroso por cuanto de noche los aviones de la fuerza aérea suelen ametrallar cualquier movimiento fluvial en determinados puntos del río. Otras consideraciones quizá más sutiles den cuenta de la extensión de la gramática social: he encontrado que algunos campesinos prefieren sintonizar, en vez de la emisora de la guerrilla, la estación de las Fuerzas Militares para no dar la impresión ante los desconocidos de que se es simpatizante de las FARC, pero lo hacen a bajo volumen porque se cree que la guerrilla sanciona a quienes escuchan la emisora del Ejército. De igual forma, aunque las acciones de

\footnotetext{
${ }^{9}$ Para entender la sedimentación en las identidades colectivas véase en el trabajo de C. Tilly (1998) 
las Fuerzas Militares son criticadas abiertamente, las críticas a la guerrilla suelen hacerse en voz baja, preferiblemente en el círculo familiar.

La gramática social ha significado que la memoria se haga selectiva y oculte, colectiva y subjetivamente, algunos sucesos sobre los que "es mejor no hablar". Por ejemplo el caso expuesto sobre el asesinato de "El Pollo"; sus vecinos y amigos lo recuerdan con cariño, pero nadie sabe dar razón sobre las causas de su muerte o sobre si ésta fue una muerte "justa". Dicho ocultamiento no significa la negación del hecho, sino la puesta en práctica de la gramática social que se sustenta en aquella conciencia colectiva, implícita y subyacente de la vida diaria. Es decir, los campesinos han de plantearse que si a "El Pollo" lo mataron por "hablador", es mejor no ser muy "hablador". Esta historia hace parte de un pasado que como otras tantas historias de la región encarnan un carácter de "conocimiento venenoso"10".

La reconfiguración de las relaciones sociales no solamente se presenta en aspectos simbólicos propios del registro de lo imaginario, las narrativas y los actos narrativos, sino también en aspectos propios de la estructura territorial. Este tipo de reconfiguración que da sentido al sufrimiento (Das, 1997: 223) es posible observarlas en el caso de Don Rogelio. La experiencia de este campesino al verse detenido, acusado y preso por el ejército, sin apoyo de su comunidad, condujo a que racionalizara su historia de tal forma que su respuesta fuese el cambiarse de vereda, sin que ello significase irse de su finca y transformar su vida campesina.

Son estas manifestaciones de la "violencia de la vida diaria" las que reproducen la existencia social en un marco de múltiples expresiones cuyo resultado no es producto de una naturaleza humana uniforme (Kleinman 2000). Son producto principalmente, de aquel control social y de la normalización de la población (en el sentido que lo sugiere Focault, 2003: 182) impuestos desde un orden guerrillero, y en pugna con la pretensión institucional de "retomar" la autoridad en el territorio.

Este enfrentamiento se constituye entre pretensiones hegemónicas que encuentran como campo de luchas no solo el plano militar sino también la organización social de la región. El "consentimiento activo" de la población del que hablase Gramsci (Dagnino, 2001), en La Macarena se hace presente en cuanto a la

10 Veena Das plantea que ante la importancia de hallar caminos para hablar sobre lo vivido (witnessing), cuando se encuentra que una vía del estar con otros fue brutalmente herida, entonces el pasado entra en el presente no necesariamente como memoria traumática sino como conocimiento venenoso (1997:221) 
relación que existe entre las comunidades campesinas y la guerrilla (en casos como la resolución de conflictos), es un punto crucial que ha de ser analizado para comprender las formas como la disciplina y el poder disciplinario (Foucault, 2003: 175) se reproducen por medio de la gramática social, incluso de manera consciente, en escenarios de guerra y conflicto social.

Siendo así, esta serie de consideraciones y la introducción de la dimensión del "sufrimiento social" al análisis sobre la violencia en la región sugieren una serie de retos que le esperan a los estudios sobre la violencia en el país. Punto crucial para plantear estrategias del tan mencionado (y todavía lejano) posconflicto que desde el actual gobierno y organizaciones de la sociedad civil se agencia, pues integrar aquellas lejanas regiones y sus formas sociales a un futuro orden nacional donde la guerra y sus marcos reguladores hayan sido superados, implica en primera instancia conocer dichas regiones, sus órdenes sociales y las formas como operan regionalmente las prácticas y respuestas al sufrimiento asociado al conflicto armado.

\section{Referencias bibliográficas}

Blair, Elsa (2005). Muertes violentas. La teatralización del exceso. Medellín: Iner.

Cubides, Fernando (1998). Las Violencias: Inclusión Creciente. Bogotá: Centro de Estudios Sociales, Universidad Nacional.

Dagnino, Evelina (2001). Cultura, ciudadanía y democracia: los discursos y practicas cambiantes en la izquierda latinoamericana. En Cultura política y política cultural, Arturo Escobar, Ed. Bogotá: Taurus

Das, Veena (1997). Language and Body: transactions in the construction of pain En Social Suffering. Arthur Kleinman et al., Eds. Berkeley: University of California Press.

Das, Veena (1998). The act of witnessing. En Violence and subjectivity. Arthur Kleiman et al., Eds. Berkeley: University of California Press

Das, Veena (1994). Moral orientations to suffering: Legitimation, power and healing En Health and social change in international perspective. Arthur Kleinman et al., Eds. Boston: Harvard University Press

Elias, Norbert (1998). Apuntes sobre el concepto de lo cotidiano. En La Civilización: de los padres y otros ensayos. Bogotá: Editorial Norma

Escobar, Arturo (2001). Cultura política y política cultural. Bogotá: Taurus

Espinosa, Nicolás (2003). A la otra orilla del río: la relación entre la guerrilla y los campesinos de La Macarena. Tesis Doctoral, Universidad Nacional, Sociología. Bogotá.

Farmer, Paul (2003). Pathologies of power. Berkeley: University of California Press.

Foucault, Michel (2003). Vigilar y Castigar. México: Siglo XXI 
Guzman, German et al. (2005) [1962]. La Violencia en Colombia. Bogotá: Taurus

Kleinman, Arthur et al., Eds. (1997). Social Suffering. Berkeley: University of California Press

Kleinman, Arthur, Ed. (1998). Violence and subjectivity. Berkeley: University of California Press.

Kleinman, Arthur, Ed. (2001). Remaking a world.. Berkeley: University of California Press.

Kleinman, Arthur y Kleinman, Joan (1997). The Appeal of experience; The dismay of images: Cultural appropriations of Suffering in our times. En Social Suffering. Arthur Kleinman et al., Eds. Berkeley: University of California Press.

Lawrence, Patricia (1998). Violences, suffering, Amman: the work of Oracles in Sri Lanka's Eastern War Zone. En Violence and subjectivity. Arthur Kleinman et al., Eds. Berkeley: University of California Press

Marcus E. G. (1995). Ethnography in/of the World System: The emergence of Multi-sited Ethnography. Annual Review of Anthropology, 24, 94-117

Martín Baró, Ignacio (1990). Psicología social de la guerra; trauma y terapia. San Salvador: UCA Editores

Molano, Fernando (1989). "Yo le digo una de las cosas...". Colonización de la Sierra de La Sierra de La Macarena. Bogotá: Fondo FEN y Corporación Araracuara

Mora, Martín (2002). La teoría de representaciones sociales de Sergei Moscovici. Athenea Digital, 2 [http://psicologiasocial.uab.es/atenea]

Rosaldo, Renato (1991). Subjetividad en el Análisis Social. En Cultura y Verdad. Nueva Propuesta de Análisis Social. México: Grijalbo.

Ruiz, Daniel (2002). Imaginarios sobre la Colonización, la Naturaleza y la Insurgencia en La Macarena-Meta. Falacia y representación. Tesis de grado. Antropología, Universidad Nacional.

Scheper-Hughes, Nancy (1992). Death Without Weeping: The Violence of Everyday Life in Brazil. Berkeley: University of California Press

Sierra, Fanny et al. (1995). Pobladores de la selva. Bogotá: ICAHN

Spencer, Jonathan (1998). On not becoming a terrorist: problems of memory, agency and community in the Sri Lanka conflict. En Violence and subjectivity. Arthur Kleinman et al., Eds. Berkeley: University of California Press

Suárez Orozco, Martín (1990). Speaking of the unspeakable: toward a psychosocial understanding of responses to terror. Ethos, 18(3), 353-383

Thoumi, Francisco, Ed. (1997). Drogas Ilícitas en Colombia. Bogotá: Ariel

Tilly, Charles (1998). Conflicto político y cambio social. En Los Movimientos Sociales: transformaciones políticas y cambio cultural. Pedro Ibarra, Ed. Madrid: Trotta.

Tokatlian, Juan Gabriel (1997). Política internacional contra la droga. En Drogas Ilícitas en Colombia, Francisco Thoumi, Ed. Bogotá: Ariel

Trejo, Alexandra (n.d.) Los Procesos de Colonización vistos desde una mirada de Género. Un estudio de caso en el municipio de La Macarena. Tesis Universidad Nacional, Antropología. Bogotá. 
Whickham ,C. Thimoty (1997). Guerrillas \& revolution in Latin America. Princeton: Princeton University Press.

Young, Allan (1997). Suffering and the origins of traumatic memory. En Social Suffering. Arthur Kleinman et al., Eds. Berkeley: University of California Press. 